\title{
Interaction of Thymidine with Sodium bis(2-ethylhexyl)Sulfosuccinate in Alcohol and Water: Studies with UV-Vis Technique
}

\author{
Indu M. Paudel ${ }^{1}$, Ajaya Bhattarai ${ }^{2 *}$ \\ ${ }^{1}$ Department of Chemistry, Central Campus of Technology, Tribhuvan University, Hattisar, Dharan, Nepal \\ ${ }^{2}$ Department of Chemistry, M.M.A.M.C., Tribhuvan University, Biratnagar, Nepal
}

\section{ARTICLE HISTORY \\ Received: June 2019 \\ Revised: October 2019 \\ Accepted: April 2020}

*Corresponding author

Email:bkajaya@yahoo.com

\begin{abstract}
The accurate measurement of thymidine absorbance in the presence of sodium bis(2-ethylhexyl) sulfosuccinate (AOT) in ethanol and water systems at room temperature by UV-vis technique has been reported. The AOT concentrations varied from 0.0005 to $0.014[\mathrm{~mol} / \mathrm{L}]$ in ethanol whereas from 0.0002 to $0.042[\mathrm{~mol} / \mathrm{L}]$ in water. The concentration of thymidine was $0.0073[\mathrm{~mol} / \mathrm{L}]$ during UV-vis spectrum registration. The thymidine spectrum was examined in the presence of AOT concentration. Using a statistical method of non-linear regression (NLREG), thymidine binding and thymidine distribution constants were evaluated. A noticeable decrease in thymidine absorbance in the presence of AOT concentration was shown in the water system; whereas, in the ethanol system, just the opposite trend has been found. The results are discussed in the context of binding and distribution constants in the studied systems.
\end{abstract}

Keywords: thymidine; sodium bis(2-ethylhexyl)sulfosuccinate; UV-vis technique

\section{INTRODUCTION}

Thymidine is a very popular pyrimidine nucleoside constituted of the pyrimidine-base thymine linked to the sugar deoxyribose. It is found in all living organisms as well as in DNA viruses. As a component of DNA, thymidine pairs with adenine in the DNA double helix. Few are the listed works on some thymidine analogs (Kim \& Kool, 2004; Adams et al., 1997), and there is a huge work on thymidine kinase (Kit et al., 1974; MunchPetersen et al., 1993), and thymidine phosphorylase (Stark et al., 2010). Thymine nucleotides are precursors of DNA, the prefix "deoxy" is usually kicked out. So deoxythymidine is usually known as thymidine. DFT calculations and resonance Raman spectroscopy have been used to study the properties of the aqueous solution of thymidine (Zhu, et al., 2008). As a chemical compound thymidine is a white substance, not hygroscopic, not sensitive to light and oxygen. It is easily soluble in water, alcohol.

AOT is a highly studied anionic surfactant because of its solubility in the most of the solvents and is generally formed the reversed micelles in non-polar solvents (Pileni, 1989; Luisi et al., 1986; Menger \& Soito, 1978; Fendler, 1987; Liu \& Guo, 2005; Long et al., 2004; Kozlov \& Andelman, 1996; Wennerström, 1996; Kotlarchyk et al., 1982; Lee \& Wyn, 1993). Hence it is widely utilized because of its capacity for the formation of micellization (Bhattarai \& Wilczura-Wachnik, 2016; Bhattarai \& Wilczura-Wachnik, 2014). The molecules of AOT have an ability of self-aggregation and hence their nature is amphiphilic. Scientifically, AOT micelles can solubilize into the inner portion of remarkable water contents (Pileni, 1989; Maitra, 1984; Bohidar \& Behboudnia, 2001) whereas from a physicochemical way, AOT micelles is one-phase water in oil microemulsion. Such an AOT system is transparent, optically isotropic as well as thermodynamically stable (Bhattarai \& Wilczura-Wachnik, 2015). The capacity of AOT molecules to produce aggregates that are developed as inner cores resided by the hydrophilic head-groups covered by the hydrocarbon tails which are elaborated into the bulk of non-polar solvent (Bhattarai \& WilczuraWachnik, 2013). It is noticed that the typical ability of AOT micelles for excess water content depends on the surrounding temperature and solvent (Menger \& Soito, 1978).

As far as we know, there are not many researches in the literature dealing with thymidine with the surfactants (Bhattarai, et al., 2017). There is no work reported yet of thymidine with AOT. The main aim is to see the interaction of thymidine with AOT in ethanol and water respectively by UV-vis spectrum. The binding constant is a particular case of the equilibrium constant and linked with the binding and unbinding phenomena of the receptor (R) and ligand (L) molecules and also, the distribution constant is the partition ratio which is the equilibrium constant for distributing the analyte in two non-miscible solvents. Hence the binding and distribution constants of thymidine are to be calculated. 


\section{METHODS}

AOT (99\%, Sigma Aldrich) was obtained from Germany, and was dried under vacuum at room temperature. Thymidine not less than $98 \%$ was received from $\mathrm{BDH}$ Chemicals Ltd Poole, England. Ethanol was obtained from Merck, India (99\% purity). Additionally, ethanol quality was checked by UV-vis methods before using. Doubled distilled water was used. As much as $0.088 \mathrm{~g}$ of thymidine was added to $50 \mathrm{ml}$ of solvent. The solution was stirred with the help of a magnetic stirrer for 5 hours.

To get the transparent solution of thymidine, MillexLCR $0.5 \mu$ filter was used to filter. AOT (5.2978 g) was added to a $100 \mathrm{ml}$ solvent. The solution was stirred with the help of a magnetic stirrer for 5 hours. The solution became transparent. Thymidine concentration in cuvette was $0.0073[\mathrm{~mol} / \mathrm{L}]$. AOT concentrations varied from 0.00023 to $0.042[\mathrm{~mol} / \mathrm{L}]$.

UV-vis measurements were done by using a single-beam Microprocessor UV vis Spectrophotometer (LT- 290 Model, India). The same procedure was used for this system from the earlier literature (Bhattarai \& WilczuraWachnik, 2014). In all cases, the experiments were performed at least in three replicates.

\section{RESULTS AND DISCUSSION}

UV-vis spectrum of thymidine is solvent dependent. It has been found that the higher the dielectric constant of the solvent, the higher the absorbance of the thymidine (Figure 1).

In both the solvents (water and ethanol), two absorption bands were located at the same lambda: a band I at 298 $\mathrm{nm}$, and band II between 250-300 $\mathrm{nm}$.

The results obtained showed a noticeable increase in thymidine absorbance in the presence of AOT concentration in the ethanol system (Table 1 and Figure 2) whereas the decrease in thymidine absorbance in the presence of AOT concentration in water system (Table 2 and Figure 3) respectively.

Thymidine molecules have been assumed as distribution between the solvent and micellar phase according to Nernstian law. To describe quantitatively the partitioning of solute molecules between AOT micelles and solvent, the total absorption of solute $(A)$ has been described as a participation of the fraction of solute solubilized in micelles $\left(x_{\mathrm{m}}\right)$ and the solvent $\left(1-x_{\mathrm{m}}\right)$ and it follows that: $A=x_{\mathrm{m}} A_{\mathrm{m}}+\left(1-x_{\mathrm{m}}\right) A_{\mathrm{o}}$

Table 1. Data of UV-vis absorbance by thymidine-AOT in the ethanol system

\begin{tabular}{lllll}
\hline \multirow{2}{*}{ AOT Concentration (M) } & \multicolumn{4}{c}{ Absorbance } \\
\cline { 2 - 5 } & Reading 1 & Reading 2 & Reading 3 & Average \\
\hline 0 & 0.167 & 0.167 & 0.167 & 0.167 \\
0.00054803 & 0.171 & 0.173 & 0.172 & 0.172 \\
0.00098504 & 0.178 & 0.179 & 0.177 & 0.178 \\
0.00237009 & 0.185 & 0.186 & 0.184 & 0.185 \\
0.00548035 & 0.192 & 0.191 & 0.193 & 0.192 \\
0.00685044 & 0.195 & 0.196 & 0.194 & 0.195 \\
0.01370090 & 0.203 & 0.203 & 0.203 & 0.203 \\
\hline
\end{tabular}

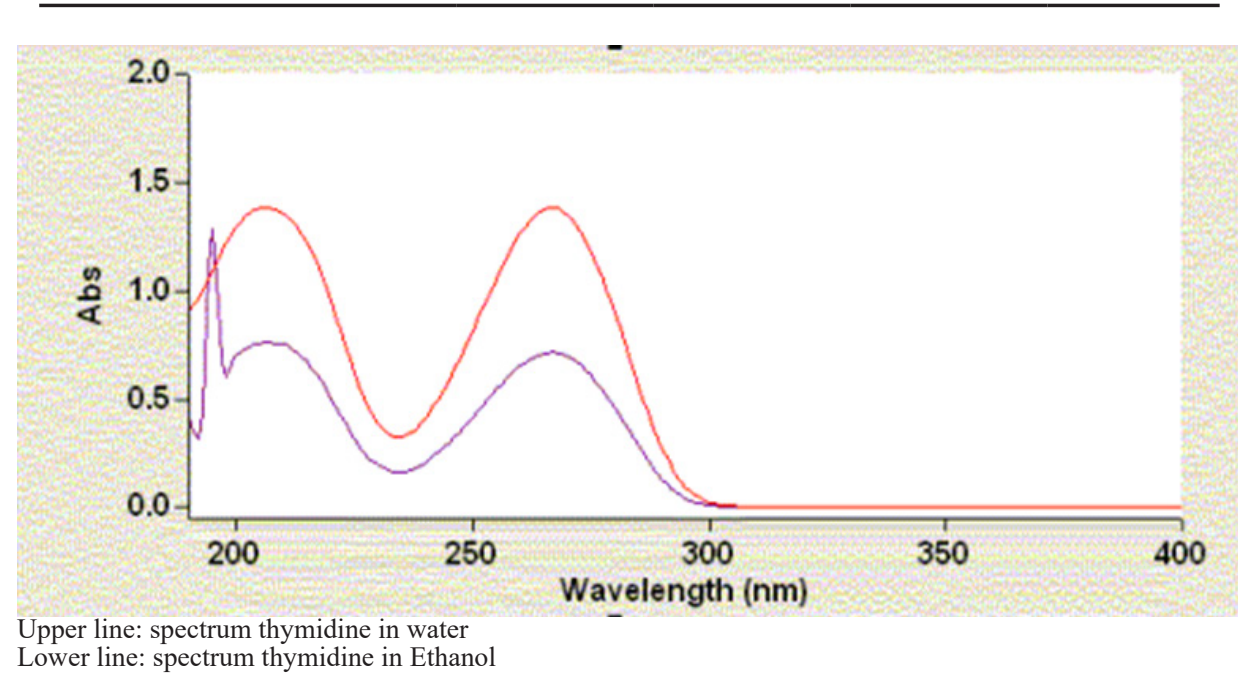

Figure 1. UV-vis spectrum of thymidine in water and ethanol 
where $A_{\mathrm{o}}$ and $A_{\mathrm{m}}$ are absorption values when a solute is totally solubilized in the pure solvent and AOT reversed micelles respectively. Following procedure developed by Magid (1981) to analyze UV-vis curves, the total solute absorption as a function of AOT concentration is given by the equation:

$A=A_{\mathrm{O}}+\frac{\left(A_{\mathrm{m}}-A_{\mathrm{o}}\right) K^{\prime}[A O T]}{1+K^{\prime}[A O T]}$

where $K^{\prime}$ is a binding constant defined as $K^{\prime}=\frac{n_{\mathrm{m}}}{[A O T] n_{\mathrm{o}}}$

There is the relation of binding constant $\left(K^{\prime}\right)$ and distribution constant $(K)$ as follows: $K^{\prime}=K M_{\text {AOT }}$ where $M_{\mathrm{AOT}}$ is the molecular weight.

In equation (2), binding constant $K^{\prime}$ and solute absorption dissolved in micellar phase $A_{\mathrm{m}}$ were the fitting parameters in NLREG procedure in which experimental UV-vis solute absorbance data were analyzed as a function of the AOT concentration. Equations and numerical values of these parameters are given in Figures 4 and 5 and compared to experimental data for the suitable solute.
The variation of absorbance with a concentration of AOT-thymidine in the ethanol system is shown in Figure 4. Similarly, the variation of absorbance with concentration of AOT-thymidine in the water system is shown in Figure 5. The obtained thymidine absorbance data as AOT concentration were analyzed in the NLREG procedure with two fitted parameters: binding constant $\left(K^{\prime}\right)$ and absorbance of thymidine associated with the micellar phase $\left(A_{\mathrm{m}}\right)$. The parameters are given in Figure 4 and Figure 5.

For system thymidine/ethanol, binding constant $\left(K^{\prime}=278\right)$ and distribution constant $(K=0.625)$ were given in the Table 3 and for system thymidine/water, binding constant $\left(K^{\prime}=17.5\right)$ and distribution constant $(K=0.039)$ were also given in the Table 3. Such low value indicates that there is a low probability for thymidine molecules transition from the bulk solvent (water) into AOT micelles.

\section{CONCLUSION}

Registered spectra showed two absorption bands with the maximum at $298 \mathrm{~nm}$ (bands I), and $305 \mathrm{~nm}$ (bands II)

Table 2. Data of UV-vis absorbance by thymidine-AOT in the water system

\begin{tabular}{lllll}
\hline \multirow{2}{*}{ AOT Concentration (M) } & \multicolumn{4}{c}{ Absorbance } \\
\cline { 2 - 5 } & Reading 1 & Reading 2 & Reading 3 & Average \\
\hline 0 & 0.290 & 0.290 & 0.289 & 0.290 \\
0.00023138 & 0.286 & 0.285 & 0.287 & 0.286 \\
0.00925521 & 0.260 & 0.261 & 0.259 & 0.260 \\
0.01388280 & 0.249 & 0.250 & 0.248 & 0.249 \\
0.02545840 & 0.225 & 0.224 & 0.226 & 0.225 \\
0.03007940 & 0.212 & 0.212 & 0.211 & 0.212 \\
0.03239330 & 0.207 & 0.206 & 0.207 & 0.207 \\
\hline
\end{tabular}

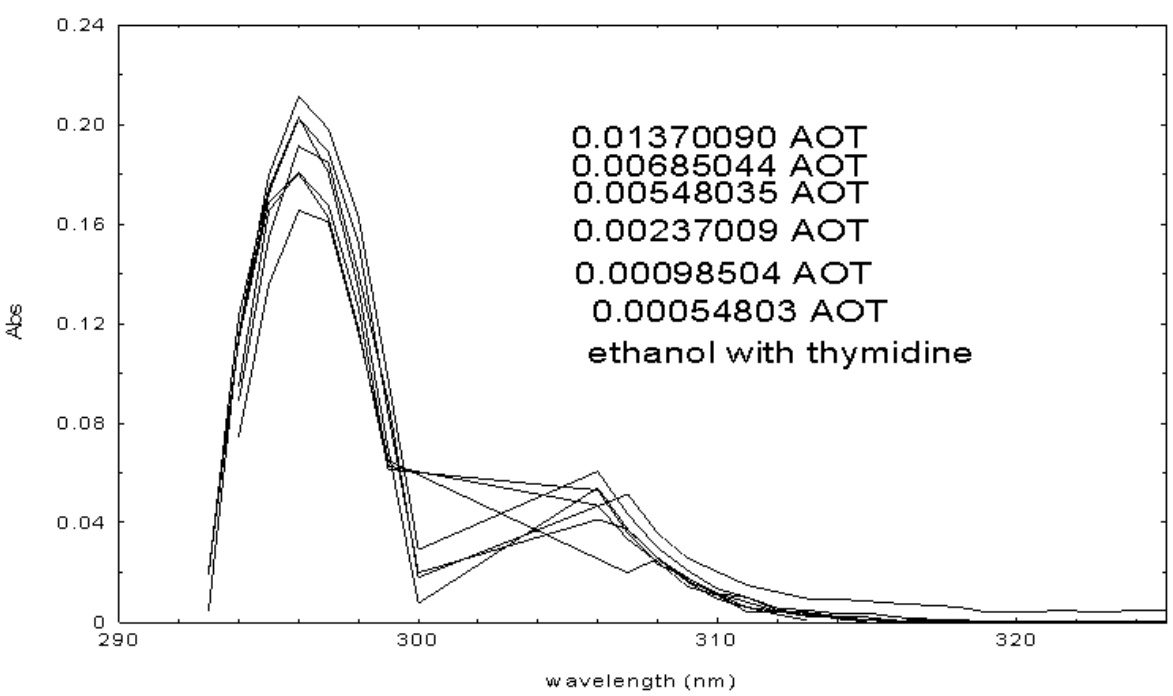

Figure 2. Thymidine absorbance as a function of AOT concentration in ethanol 
Table 3. The fitting parameters $\left(A_{\mathrm{m}}\right.$ and $\left.K^{\prime}\right)$ obtained in the Non-linear regression procedure of the UV-Vis data and $K$ (distribution constant obtained from the relation: $K^{\prime}=K M_{\mathrm{AOT}}$ )

\begin{tabular}{lll}
\hline$A_{\mathrm{m}}$ & Binding Constant $\left(K^{\prime}\right)$ & Distribution Constant $(K)$ \\
\hline 0.211 (Ethanol) & 278 & 0.625 \\
0.0728 (Water) & 17.5 & 0.039 \\
\hline
\end{tabular}

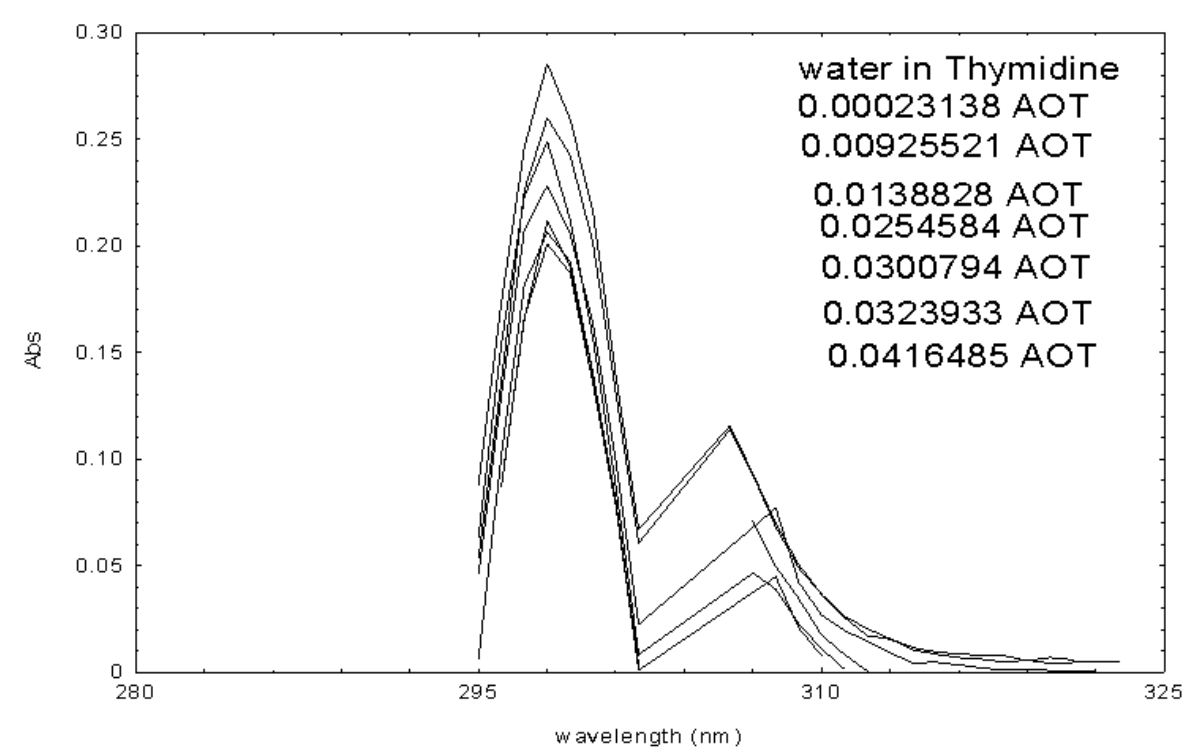

Figure 3. Thymidine absorbance as a function of AOT concentration in water

in both solvents. It was found the solvent influences the thymidine absorption values. The intensity of the band I in water is higher as compared to ethanol. It indicates stronger interactions between ethanol and thymidine as compared to thymidine-water. From the above results and discussion for the studied systems: thymidine/ ethanol/AOT and thymidine/water/ AOT, it has been found that: thymidine/ethanol/AOT has the higher value of binding constant as evidence of stronger interactions between thymidine molecules and AOT in ethanol compared to that of thymidine molecules and AOT in water. The 16 times higher distribution constant value for thymidine molecules-AOT in ethanol indicates that they transit more easily from solvent to AOT micellar phase compared to thymidine molecules-AOT in water.

\section{ACKNOWLEDGMENT}

One of the authors (Indu M. Paudel) acknowledges the Dean's office of Institute of Science and Technology, Tribhuvan University, Kathmandu, Nepal for the partial financial support on this work.

\section{REFERENCES}

Adams, D. R., Perez, C., Maillard, M., Florent, J.-
C., Evers, M., Hénin, Y., ... Grierson, D. S. (1997). Preparation and anti-HIV activity of N-3-Substituted thymidine nucleoside analogs. Journal of Medicinal Chemistry, 40(10), 1550-1558. https://doi.org/10.1021/ jm9600095.

Bhattarai, A., \& Hanna, W. (2016). UV-Vis Spectrophotomertic Investigation of \&\#946;-Carotene and Morin in Presence of AOT/Ethanol System. Journal of Surface Science and Technology, 32(1-2), 16. https:// doi.org/10.18311/jsst/2016/6597.

Bhattarai, A., \& Wilczura-Wachnik, H. (2014). Interaction between morin and AOT reversed micellesStudies with UV-vis at $25^{\circ} \mathrm{C}$. International Journal of Pharmacentics, 461(1-2), 14-21. https://doi. org/10.1016/j.ijpharm.2013.11.003.

Bhattarai, A., \& Wilczura-Wachnik, H. (2015). Size and diffusion phenomena of AOT/alcohol/water system in the presence of morin by dynamic light scattering. International Journal of Pharmaceutics, 478(2), 610616. https://doi.org/10.1016/j.jpharm.2014.11.037.

Bhattarai. (2013). UV-vis Investigation of $\square$-Carotene in Presence of AOT/n-Heptane, Cyclohexane, 


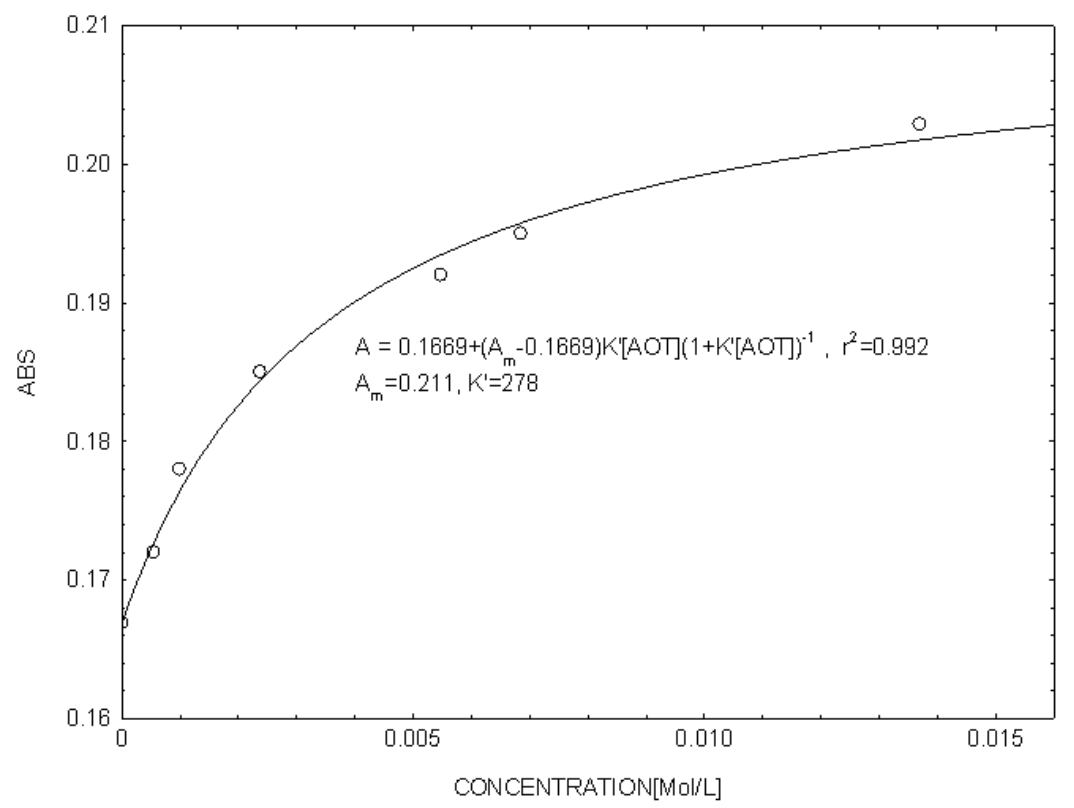

Figure 4. Variation of Absorbance with Concentration of AOT-thymidine in ethanol system Points-experimental data, solid lines are the best fitting curves in NLREG

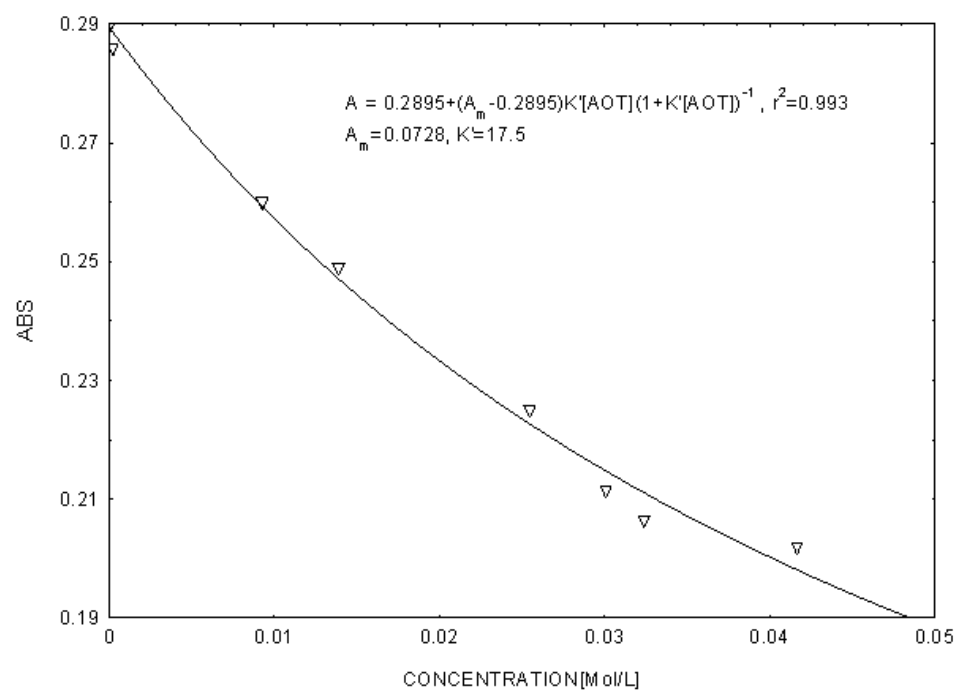

Figure 5. Variation of Absorbance with Concentration of AOT-thymidine in the water system Points-experimental data, solid lines are the best fitting curves in NLREG

Tetrahydrofuran/Water System. Journal of Applied Solution Chemistry and Modeling. https://doi. org/10.6000/1929-5030.2013.02.04.7.

Bhattarai, A., Wachnik, H. W., \& Grzegorek, M. (2017). The solvent influence on thymidine-SDS alcohol micelle system: Studies with UV-Vis technique. American Journal of Pharmacology and Pharmacotherapeutics, 4 (3), 8-22.

Bohidar, H. B., \& Behboudnia, M. (2001). Characterization of reverse micelles by dynamic light scattering. Colloids and Surfaces A: Physicochemical and Engineering Aspects, 178(1-3), 313-323. https:// doi.org/10.1016/s0927-7757(00)00736-6.

Fendler, J. H. (1987). Atomic and molecular clusters in membrane mimetic chemistry. Chemical Reviews, 87(5), 877-899. https://doi.org/10.1021/cr00081a002

Kim, T. W., \& Kool, E. T. (2004). A set of nonpolar thymidine nucleoside analogues with gradually increasing size. Organic Letters, 6(22), 3949-3952. https://doi.org/10.1021/o1048487u. 
Kit, S., Leung, W.-C., Jorgensen, G. N., \& Dubbs, D. R. (1974). Distinctive properties of thymidine kinase isozymes induced by human and avian herpesviruses. International Journal of Cancer, 14(5), 598-610. https:// doi.org/10.1002/ijc.2910140506.

Kotlarchyk, M., Chen, S. H., \& Huang, J. S. (1982). Temperature dependence of size and polydispersity in a three-component microemulsion by small-angle neutron scattering. The Journal of Physical Chemistry, 86(17), 3273-3276. https://doi.org/10.1021/j100214a001

Kozlov, M. M., \& Andelman, D. (1996). Theory and phenomenology of mixed amphiphilic aggregates. Current Opinion in Colloid \& Interface Science, 1(3), 362-366. https://doi.org/10.1016/s1359-0294(96)801348

Lee, M., \& Wyn, B. (1993). Dynamic Light Scattering: The Method and Some Applications. Clarendon Press, Oxford University Press, pp. 554-593 Chapter 13.

Liu, W., \& Guo, R. (2005). The interaction between morin and CTAB aggregates. Journal of Colloid and Interface Science, 290(2), 564-573. https://doi.org/10.1016/j. jcis.2005.04.061

Long, X., Bi, S., Ni, H., Tao, X., \& Gan, N. (2004). Resonance Rayleigh scattering determination of trace amounts of Al in natural waters and biological samples based on the formation of an Al(III)-morin-surfactant complex. Analytica Chimica Acta, 501(1), 89-97. https:// doi.org/10.1016/j.aca.2003.09.024

Luisi, P. L., Magid, L. J., \& Fendler, J. H. (1986). Solubilization of Enzymes and Nucleic Acids in Hydrocarbon Micellar Solution. Critical Reviews in Biochemistry, 20(4), 409-474. https://doi. org/10.3109/10409238609081999

Magid, L. J., Konno, K., \& Martin, C. A. (1981). Binding of phenols to inverted micelles and microemulsion aggregates. The Journal of Physical Chemistry, 85(10), 1434-1439. https://doi.org/10.1021/j150610a031
Menger, F. M., \& Saito, G. (1978). Adsorption, displacement, and ionization in water pools. Journal of the American Chemical Society, 100(14), 4376-4379. https://doi.org/10.1021/ja00482a010.

Maitra, A. (1984). Determination of size parameters of water-Aerosol OT-oil reverse micelles from their nuclear magnetic resonance data. The Journal of Physical Chemistry, 88(21), 5122-5125. https://doi.org/10.1021/ j150665a064.

Munch-Petersen B., Tyrsted G., \& Cloos L.(1993). Reversible ATP-dependent transition between two forms of human cytosolic thymidine kinase with different enzymatic properties. Journal of Biological Chemistry, $268,15621-15625$.

Pileni, M.P. (1989). Structure and reactivity in reversed micelles. In: Langevin, D. (Ed.), Structure of Reversed Micelles. Elsevier, Amsterdam, pp. 13-44.

Stark, M., Bram, E. E., Akerman, M., Mandel-Gutfreund, Y., \& Assaraf, Y. G. (2010). Heterogeneous Nuclear Ribonucleoprotein H1/H2-dependent Unsplicing of Thymidine Phosphorylase Results in Anticancer Drug Resistance. Journal of Biological Chemistry, 286(5), 3741-3754. https://doi.org/10.1074/jbc.m110.163444

Wennerström, H. (1996). Thermodynamic theory of surfactant phases. Current Opinion in Colloid \& Interface Science, 1(3), 370-375. https://doi.org/10.1016/s13590294(96)80136-1.

Zhu, X.-M., Wang, H., Zheng, X., \& Phillips, D. L. (2008). Role of Ribose in the Initial Excited State Structural Dynamics of Thymidine in Water Solution: A Resonance Raman and Density Functional Theory Investigation. The Journal of Physical Chemistry B, 112(49), 1582815836. https://doi.org/10.1021/jp806248b. 